OPEN ACCESS

Edited by:

Mauricio Antonio Retamal, Universidad del Desarrollo, Chile

Reviewed by:

Eliseo A. Eugenin,

Rutgers University-Newark,

United States

Juan C. Saez,

Pontificia Universidad Católica de Chile, Chile

*Correspondence: Rosalba Parenti parenti@unict.it

${ }^{\dagger}$ These authors have contributed equally to this work.

Specialty section:

This article was submitted to Membrane Physiology and Membrane

Biophysics,

a section of the journal

Frontiers in Physiology

Received: 06 October 2017 Accepted: 04 December 2017 Published: 18 December 2017

Citation:

Vicario N, Zappalà A, Calabrese G,

Gulino R, Parenti C, Gulisano M and

Parenti $R$ (2017) Connexins in the

Central Nervous System: Physiological

Traits and Neuroprotective Targets.

Front. Physiol. 8:1060.

doi: 10.3389/fphys.2017.01060

\section{Connexins in the Central Nervous System: Physiological Traits and Neuroprotective Targets}

\author{
Nunzio Vicario ${ }^{1 \dagger}$, Agata Zappalà ${ }^{1 \dagger}$, Giovanna Calabrese ${ }^{1}$, Rosario Gulino ${ }^{1}$, \\ Carmela Parenti ${ }^{2}$, Massimo Gulisano ${ }^{1,2}$ and Rosalba Parenti ${ }^{1 *}$ \\ ${ }^{1}$ Section of Physiology, Department of Biomedical and Biotechnological Sciences, University of Catania, Catania, Italy, \\ ${ }^{2}$ Department of Drug Sciences, University of Catania, Catania, Italy
}

Cell-to-cell interaction and cell-to-extracellular environment communication are emerging as new therapeutic targets in neurodegenerative disorders. Dynamic expression of connexins leads to distinctive hemichannels and gap junctions, characterized by cell-specific conduction, exchange of stimuli or metabolites, and particular channel functions. Herein, we briefly reviewed classical physiological traits and functions of connexins, hemichannels, and gap junctions, in order to discuss the controversial role of these proteins and their mediated interactions during neuroprotection, with a particular focus on Cx43-based channels. We pointed out the contribution of connexins in neural cells populations during neurodegenerative processes to explore potential neuroprotective therapeutic applications.

Keywords: gap junction, hemichannel, connexin, neurodegeneration, neuroprotection

\section{INTRODUCTION}

Gap junctions (GJs) are pivotal for the development and maintenance of physiological arrangement of multicellular organisms (Kandler and Katz, 1998; Krüger et al., 2000; Roerig and Feller, 2000), playing fundamental roles in a wide range of cellular activities, including cell signaling, differentiation, and growth (Goodenough et al., 1996). These structures act as molecular substrate of intercellular communication constituting so called plaques at sites of cell-to-cell interface but also mediating GJs-independent signaling (Jiang and Gu, 2005; Zhou and Jiang, 2014). In fact, connexins (Cxs), which represent the core proteins of GJs, also organize free hemichannels (HCs) throughout the plasma membrane, allowing complex chemical trafficking between cytoplasm and the extracellular environment (Cherian et al., 2005; Spray et al., 2006).

Disruption of GJs, HCs, and Cxs balance, affecting the finely regulated expression in healthy tissues, allows cell elusion from normal physiological behavior by driving them to pathological conditions with different degrees of severity, including cancer and degenerative processes (Decrock et al., 2015b; Belousov et al., 2017). As such, Cxs expression in tissues and organs from embryo to adult throughout life is strictly regulated. This control is particularly emphasized during the developmental process, in which Cxs levels alterations lead to profound impairment of tissue functions up to lethal phenotypes (Bruzzone et al., 1996; Davies et al., 1996).

In particular, Cxs, GJs, and HCs in the central nervous system (CNS) have always been in the spotlight of research about homeostatic glia/neuron activities as well as aberrant organization in different neurological disorders (Parenti et al., 2010; Orellana et al., 2014; Li et al., 2015; Belousov et al., 2017). In the past years, much interest has been placed on neuroprotective and self-repair processes in the CNS as a tool to approach neurodegenerative disorders. 


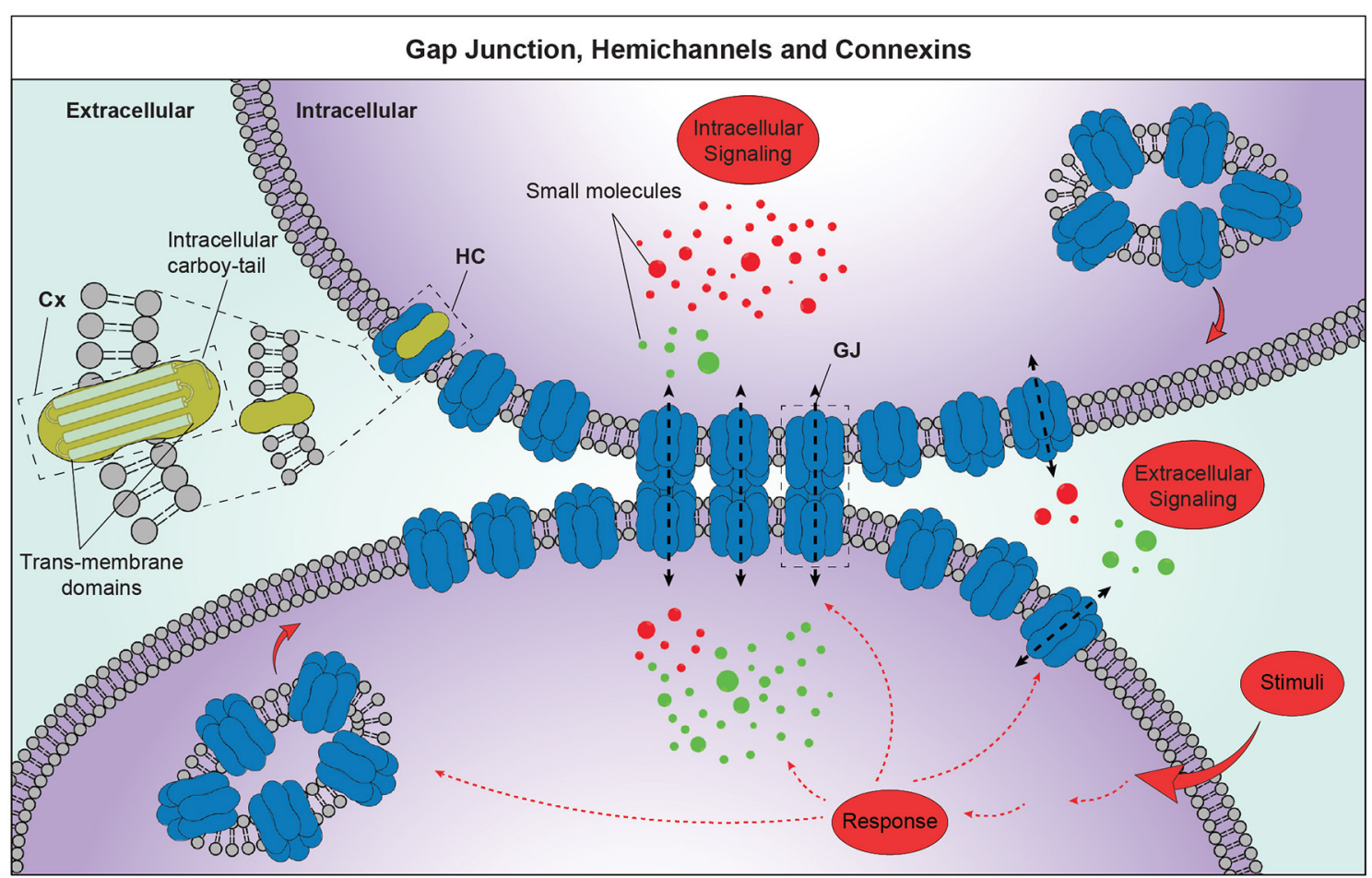

FIGURE 1 | Schematic representation of GJ intercellular communication (GJIC) and HC-mediated cell-to-extracellular environment communication. CxS, composed by 4 transmembrane domains and an intracellular carboy-tail, are organized to homomeric or heteromeric HCs. GJ plaques are structures of hundreds up to thousands of single channels, which mediate exchanges of small molecules, substrates and metabolites. Those structures show free HCs exposed to the plaque border, where each cell adds newly synthetized HCs. These structures are crucial players of the GJIC and HCs-mediated cell-to-extracellular environment communication and lead to the information exchanges between neighboring cells favoring synchronized and concerted responses. Cx, connexin; HC, hemichannel; GJ, gap junction.

However, the molecular mechanisms underpinning the neuroprotective and regenerative processes are far to be fully elucidated and the exploitation of such a promising approach still remains elusive. In this field, GJs- and HCs-based signaling is one of the most controversial mechanisms that take place during degenerative and repairing processes (Andrade-Rozental et al., 2000). Research focused on these pathways, which takes advantages from pharmacological modulators, gene editing and emerging high resolution imaging techniques, represents an intriguing effort among all the explored neuroprotective strategies in both in vitro and in vivo experimental models (Beyer and Berthoud, 2002; Wong et al., 2016).

\section{STRUCTURAL PROPERTIES AND FUNCTIONS IN THE CENTRAL NERVOUS SYSTEM (CNS)}

Cxs are encoded by 21 genes in human, each one named according to its theoretical molecular mass in $\mathrm{kDa}$ (Willecke et al., 2002). They are structural transmembrane proteins composing HCs, also named connexons, which dock plasma membranes of adjacent cells forming GJs (Bruzzone et al., 1996; White and Bruzzone, 1996). GJs aggregate in specific plasma membrane regions of adjacent cells forming GJ plaques, which are dynamic macrostructures easily assembled, disassembled, or remodeled configuring a very eventful scenario. In physiological conditions, new HCs are constantly added to the periphery of existing plaques and remain in an inactive conformation until they are aligned with HCs of adjacent cells, while old HCs are removed from the central portion to be destroyed (Gaietta et al., 2002; Figure 1). Finally, Cxs have a few hours half-life, kinetics that are particularly short compared to other plasma membrane proteins (Laird et al., 1991; Lampe, 1994; Beardslee et al., 1998).

Most functions of $\mathrm{Cx}$-formed structures depend on Cxs dynamicity, including different Cxs combinations that convey specific permeability properties and features. In fact, Cxs subunits shape channel conductance, modulate electrical communication and control metabolic coupling between cells (White and Bruzzone, 1996; Salas et al., 2015; Karagiannis et al., 2016). Notably, it is crucial to take into consideration Cxs direct and indirect interactions, which affect many physio-pathological functions (Bruzzone et al., 1996; Cina et al., 2009; Zappalà et al., 2010; Saidi Brikci-Nigassa et al., 2012). On this regard the cytoplasmic tail of Cxs, plays a prominent dynamic role showing different phosphorylation sites and loci dedicated to the interaction with other cytoplasmic proteins, modifying the activity of the whole channel (Matsuuchi and Naus, 2013; Kotini and Mayor, 2015). 
GJs, HCs, and Cxs play crucial roles in CNS throughout life for several physiological processes being anatomical substrates for electrical and metabolic synchronism. Their importance is evident from the early stages of development, when GJs intercellular communication (GJIC) and cell-to-extracellular environment communications are key events to establish connections, compartmentalization, differentiation, and finally, cell identity (Davies et al., 1996; Bittman et al., 2002; Cina et al., 2007). Even if during adult life some fully differentiated cells do not express high Cxs levels, including some neurons in addition to mature skeletal muscle fibers, red blood cells, and spermatozoids (Bruzzone et al., 1996; Willecke et al., 2002), electrical and metabolic intercellular through GJ- and HC-based coupling remain fundamental in CNS of the adult phenotype (Perlman and Ammermüller, 1994). Cxs also play channel-independent role in cell adhesion, migration, formation of neuronal networks, cellular division, differentiation, and tumorigenicity, acting also synergistically with membranous tunneling tubes (Rimkute et al., 2016). In particular, cell adhesion and migration are key functions during CNS development early in embryonic neuroepithelium and neural migration in neocortex by providing contact interfaces with radial glia (Elias et al., 2007) or along the rostral migratory route of subventricular zone-derived cells (Marins et al., 2009). Cell adhesion is further maintained for astrocytic network stabilization in mature CNS (Haubrich et al., 1996; Lin et al., 2002). Here, complex levels of Cxs organization create a functional unit, named neuro-gliovascular unit, maintaining both direct cell-cell coupling, via GJIC and paracrine communication via the extracellular compartment properties (Decrock et al., 2015a; De Bock et al., 2017).

A large number of experimental models of human diseases have revealed key Cxs functions in physio-pathological conditions, showing cell type specificity, mutual assistance and redundant role depending on the functional context in which Cxs operate (Nishii et al., 2014). In this field, research has grown and changed remarkably, starting with the discovery of new members of Cx family, describing their spatio-temporal distribution, analysing their functional role and the pathological consequences of their malfunction. In particular, in the neural lineages, Cxs ensure functions ranging from cell division to learning and memory and their disregulation, directly or indirectly conducts to many pathological conditions including epilepsy (Thompson et al., 2008), neuroinflammation (Orellana et al., 2011a; Bennett et al., 2012), neurodegeneration (Orellana et al., 2011b), ischemia (Contreras et al., 2004; Orellana et al., 2010), behavioral alterations (Wang and Belousov, 2011; Zlomuzica et al., 2012; Beheshti et al., 2017) and diverse pathological conditions, including excitotoxic cell-death (Kondo et al., 2000) and injurious depolarization (Schulz et al., 2015; Lapato and Tiwari-Woodruff, 2017).

Several approaches, aiming to modulate channel activity including phosphorylation/de-phosphorylation and nitrosylation until to knockout/knockin technology as well as pharmacological approaches, have come to support their role as emerging therapeutic target in neurodegenerative disorders (Schultz et al., 2016). Thus, by now far from the idea that GJs are simply direct connection between the cytoplasm of two cells, is becoming clear over time that GJs as well as HCs play homeostatic physiological functions whose delicate balance can be altered by leading to pathological conditions of different entities (Table 1).

\section{GJs, HCs, AND CXs: ROLE IN NEURODEGENERATION AND NEUROPROTECTION}

Neurodegenerative diseases are among the leading causes of death and disability worldwide. This has led to a growing indepth research focusing on cellular and molecular mechanisms underlying neurodegeneration to increasingly counteract this phenomenon. In human and in experimental models, a number of $\mathrm{Cx}$ alterations are differently involved in the development of various neurodegenerative diseases so much so that they are considered important therapeutic targets (Belousov et al., 2017; Charvériat et al., 2017; Liu et al., 2017). Several independent studies have pointed out that onset and progression of homeostatic imbalances observed during neurodegeneration could be associated with a GJ-independent increased membrane permeability related to HCs activity in the CNS (Retamal et al., 2007; Orellana et al., 2010; Burkovetskaya et al., 2014). In addition, increased secondary damages via cytotoxicity and inflammatory response, lead to secondary cell death and propagation of neuronal loss (O'Carroll et al., 2013; Akopian et al., 2014). This mechanism underlies a number of degenerative disorders, including retinopathies, such as glaucoma (Akopian et al., 2014, 2017), traumatic brain injury (Davidson et al., 2015b; Chen et al., 2016), stroke (Nakase et al., 2009; Orellana et al., 2014) as well as degenerative disorders of the CNS such as Alzheimer's disease (Nagy et al., 1996; Orellana et al., 2011b) and amyotrophic lateral sclerosis (ALS)-related motor neuron loss (Almad et al., 2016). These pathological conditions are characterized by reactive astrogliosis, mononuclear phagocytes activation, neuronal injury, and cell death typically linked to affected activity and regulation of main Cxs of the CNS including Cx36, Cx43, Cx30, Cx32, Cx29, and Cx47 (Decrock et al., 2015b; Belousov et al., 2017). For a specific injury and stress condition, up- or down-regulation of such proteins, likely influencing gate properties of GJs and free HCs, may contribute to both neuronal death or survival, representing the "kiss of death" and the "kiss of life," based on which $\mathrm{Cx}$ is expressed and on which level (Andrade-Rozental et al., 2000). Even more, the neuronal fate is linked to the intercellular or cell-to-extracellular environment propagation of "pro-death" and "pro-survival" permeable signals (Akopian et al., 2014; Decrock et al., 2015b; Belousov et al., 2017). This complex scenario is emphasized for $\mathrm{Cx} 43$, one of the most abundant Cxs in the CNS and main actor in mediating glial responses to CNS injury. Many studies support the potential therapeutic efficacy of $\mathrm{Cx} 43-\mathrm{GJ}$ blockade on cell survival, suggesting a role of the GJs and HCs activity in increasing secondary damages (Orellana et al., 2010; Bennett et al., 2012; O'Carroll et al., 2013). Recent scientific evidence supports a pivotal role for $\mathrm{Cx} 43$ in different mechanisms in CNS and specifically in the microenvironment of the neurovascular 
TABLE 1 | Connexins expression and main functions in neurodegeneration.

\begin{tabular}{|c|c|c|c|c|c|}
\hline Cell type & Cxs & Gene & Ranking & Functions & References \\
\hline \multirow[t]{3}{*}{ Neurons } & $\mathrm{C} \times 36$ & Gjd2 & +++++ & Memory and behavior & $\begin{array}{l}\text { Condorelli et al., 1998; Cicirata et al., 2000; Gulisano et al., } \\
\text { 2000; Parenti et al., 2000; Bittman et al., 2002; Wang and } \\
\text { Belousov, 2011; Zlomuzica et al., 2012; Beheshti et al., } 2017\end{array}$ \\
\hline & $\mathrm{C} \times 45$ & Gjc1 & + & Memory and behavior & Leung et al., 2002; Cina et al., 2007; Beheshti et al., 2017 \\
\hline & Cx50 & Gja8 & ++++ & Voltage dependent hemichannel & Beahm and Hall, 2002 \\
\hline \multirow[t]{3}{*}{ Astrocytes } & $\mathrm{C} \times 26$ & Gjb2 & +++ & Degeneration and neurotoxic signaling & $\begin{array}{l}\text { Elias et al., 2007; Takeuchi et al., 2011; Koulakoff et al., 2012; } \\
\text { Karagiannis et al., } 2016\end{array}$ \\
\hline & $\mathrm{C} \times 30$ & Gjb6 & ++ & & \\
\hline & $\mathrm{C} \times 43$ & Gja1 & ++++ & Adhesion, energy metabolism, and degeneration & $\begin{array}{l}\text { Lin et al., 1998; Elias et al., 2007; Pellerin et al., 2007; } \\
\text { Takeuchi et al., 2011; Salmina et al., 2014; Suzuki et al., } \\
\text { 2014; Salas et al., 2015; Almad et al., } 2016\end{array}$ \\
\hline \multirow[t]{3}{*}{ Oligodendrocytes } & Cx29 & Gjc3 & +++ & Remyelination and regeneration & $\begin{array}{l}\text { Altevogt et al., 2002; Nagy et al., 2003a,b; Parenti et al., } \\
\text { 2010; Markoullis et al., } 2012\end{array}$ \\
\hline & $\mathrm{C} \times 32$ & Gjb1 & +++++ & & \\
\hline & $\mathrm{C} \times 47$ & Gjc2 & ++ & & \\
\hline \multirow[t]{3}{*}{ Microglia } & $\mathrm{C} \times 32$ & Gjb1 & +++++ & Inflammation & Takeuchi et al., 2006, 2008 \\
\hline & $\mathrm{C} \times 36$ & Gjd2 & ++ & Neurotoxic signaling & Yawata et al., 2008 \\
\hline & $\mathrm{C} \times 43$ & Gja1 & + & Inflammation & Orellana et al., 2009 \\
\hline \multirow[t]{3}{*}{ Endothelial cells } & $\mathrm{C} \times 37$ & Gja4 & +++ & Regeneration and healing & Li et al., 2016 \\
\hline & $\mathrm{C} \times 40$ & Gja5 & +++++ & & \\
\hline & $\mathrm{C} \times 43$ & Gja1 & +++++ & & \\
\hline
\end{tabular}

Ranking: + , very low ++ , low +++ , medium; ++++ , high; +++++ , very high. This table includes information from more than one experimental approach.

unit, from the regulation of the blood brain barrier (BBB) to the modulation of integrative brain functions (i.e., learning, memory, and behavior), indicating $\mathrm{Cx} 43$ as an attractive target for therapeutic strategies in different brain pathologies (Salmina et al., 2014). Using a pharmacological approach we recently demonstrated a neuroprotective effect on in vitro neuron-like cultures exposed to hypoxic stress conditions reducing cellto-cell and cell-to-extracellular environment communication through carbenoxolone (non-selective GJs inhibitor), ioxynil octanoato (selective Cx43-based GJs inhibitor), and Gap19 (selective Cx43-based HCs inhibitor; Vicario et al., 2017). Our results were in accordance with previous evidences which demonstrated an abnormal and progressive increase in $\mathrm{Cx} 43$ expression, enhancing GJs-mediated coupling, and increased HCs activity, as one of the mechanisms for astrocyte-mediated toxicity in an in vivo model of neurodegenerative disorder (Almad et al., 2016). The use of both GJs or HCs blockers conferred neuroprotection also to motor neurons cultured with $\mathrm{SOD}^{1 \mathrm{G} 93 \mathrm{~A}}$ astrocytes, suggesting a detrimental role of $\mathrm{Cx} 43$ in neurodegenerative models of ALS (Almad et al., 2016). Similar protective effects of blocking $\mathrm{Cx} 43$ have been described in other neurodegenerative injury including hypoxia, ischemia, Alzheimer's disease, and glaucoma (Chew et al., 2010; Wang et al., 2014; Chen et al., 2016; Giaume et al., 2017).

However, experimental results support the idea that $\mathrm{Cx} 43$ involvement is strictly context-dependent and related to the effects of specific phosphorylation sites in the C-terminal tail and inter-protein interaction, affecting trafficking, turnover, assembly, and gating (Cooper and Lampe, 2002; Richards et al., 2004; Yoon et al., 2010; Márquez-Rosado et al., 2012; Dunn and Lampe, 2014; Davidson et al., 2015a; Schulz et al., 2015), which prevent a generalization and stimulate further investigations on Cxs involvement in neurodegenerative and neuroprotective processes.

\section{CONCLUDING REMARKS}

Our knowledge about Cxs-mediated neuroprotection is doomed to grow quickly. The possibility to potentiate endogenous neuroprotective mechanisms represents certainly a fascinating approach for powerful therapeutic applications after CNS injury. GJs and HCs involvement in maintaining the balance of CNS microenvironment strongly stimulate research toward the development of new modulators for Cxs-based channels to be used as novel therapeutic agents against CNS disorders. A number of studies have pointed out the beneficial effect of drugs targeting Cxs-based channels, paving the way to develop complementary cell-specific approaches for the treatment of a broad range of diseases. Finally, since experimental evidences solidly demonstrate that astrocytes and $\mathrm{Cx} 43$ have a prominent role in neurodegenerative processes, this cell population and its molecular tools, including Cx-based structures, are more and more going to be confirmed as the indispensable guardians of neuronal activities. 


\section{AUTHOR CONTRIBUTIONS}

All authors listed have made a substantial, direct and intellectual contribution to the work, and approved it for publication.

\section{FUNDING}

This study was supported by the University Research Project Grant (Research Plan 2016-2018), Department of Biomedical

\section{REFERENCES}

Akopian, A., Atlasz, T., Pan, F., Wong, S., Zhang, Y., Völgyi, B., et al. (2014). Gap junction-mediated death of retinal neurons is connexin and insult specific: a potential target for neuroprotection. J. Neurosci. 34, 10582-10591. doi: 10.1523/JNEUROSCI.1912-14.2014

Akopian, A., Kumar, S., Ramakrishnan, H., Roy, K., Viswanathan, S., and Bloomfield, S. A. (2017). Targeting neuronal gap junctions in mouse retina offers neuroprotection in glaucoma. J. Clin. Invest. 127, 2647-2661. doi: 10.1172/JCI91948

Almad, A. A., Doreswamy, A., Gross, S. K., Richard, J. P., Huo, Y., Haughey, N., et al. (2016). Connexin 43 in astrocytes contributes to motor neuron toxicity in amyotrophic lateral sclerosis. Glia 64, 1154-1169. doi: 10.1002/glia.22989

Altevogt, B. M., Kleopa, K. A., Postma, F. R., Scherer, S. S., and Paul, D. L. (2002). Connexin29 is uniquely distributed within myelinating glial cells of the central and peripheral nervous systems. J. Neurosci. 22, 6458-6470.

Andrade-Rozental, A. F., Rozental, R., Hopperstad, M. G., Wu, J. K., Vrionis, F. D., and Spray, D. C. (2000). Gap junctions: the "kiss of death" and the "kiss of life". Brain Res. Brain Res. Rev. 32, 308-315. doi: 10.1016/S0165-0173(99)00099-5

Beahm, D. L., and Hall, J. E. (2002). Hemichannel and junctional properties of connexin 50. Biophys. J. 82, 2016-2031. doi: 10.1016/S0006-3495(02)75550-1

Beardslee, M. A., Laing, J. G., Beyer, E. C., and Saffitz, J. E. (1998). Rapid turnover of connexin43 in the adult rat heart. Circ. Res. 83, 629-635. doi: 10.1161/01.RES.83.6.629

Beheshti, S., Zeinali, R., and Esmaeili, A. (2017). Rapid upregulation of the hippocampal connexins 36 and 45 mRNA levels during memory consolidation. Behav. Brain Res. 320, 85-90. doi: 10.1016/j.bbr.2016.11.048

Belousov, A. B., Fontes, J. D., Freitas-Andrade, M., and Naus, C. C. (2017). Gap junctions and hemichannels: communicating cell death in neurodevelopment and disease. BMC Cell Biol. 18:4. doi: 10.1186/s12860-016-0120-x

Bennett, M. V., Garré, J. M., Orellana, J. A., Bukauskas, F. F., Nedergaard, M., and Saez, J. C. (2012). Connexin and pannexin hemichannels in inflammatory responses of glia and neurons. Brain Res. 1487, 3-15. doi: 10.1016/j.brainres.2012.08.042

Beyer, E. C., and Berthoud, V. M. (2002). Gap junction synthesis and degradation as therapeutic targets. Curr. Drug Targets 3, 409-416. doi: 10.2174/1389450023347245

Bittman, K., Becker, D. L., Cicirata, F., and Parnavelas, J. G. (2002). Connexin expression in homotypic and heterotypic cell coupling in the developing cerebral cortex. J. Comp. Neurol. 443, 201-212. doi: 10.1002/cne.2121

Bruzzone, R., White, T. W., and Paul, D. L. (1996). Connections with connexins: the molecular basis of direct intercellular signaling. Eur. J. Biochem. 238, 1-27. doi: 10.1111/j.1432-1033.1996.0001q.x

Burkovetskaya, M., Karpuk, N., Xiong, J., Bosch, M., Boska, M. D., Takeuchi, H., et al. (2014). Evidence for aberrant astrocyte hemichannel activity in Juvenile Neuronal Ceroid Lipofuscinosis (JNCL). PLoS ONE 9:e95023. doi: 10.1371/journal.pone.0095023

Charvériat, M., Naus, C. C., Leybaert, L., Sáez, J. C., and Giaume, C. (2017). Connexin-dependent neuroglial networking as a new therapeutic target. Front. Cell. Neurosci. 11:174. doi: 10.3389/fncel.2017.00174

Chen, W., Guo, Y., Yang, W., Zheng, P., Zeng, J., and Tong, W. (2016). Involvement of Connexin40 in the protective effects of ginsenoside Rb1 against traumatic brain injury. Cell. Mol. Neurobiol. 36, 1057-1065. doi: 10.1007/s10571-015-0299-y and Biotechnological Sciences (BIOMETEC), University of Catania (Italy) and by the Italian Ministry of Education, University and Research (PRIN: Progetti di Ricerca di Rilevante Interesse Nazionale_Grant no. 2015MJBEM2_006).

\section{ACKNOWLEDGMENTS}

We apologize to colleagues whose work we could not cite because of space constraints.

Cherian, P. P., Siller-Jackson, A. J., Gu, S., Wang, X., Bonewald, L. F., Sprague, E., et al. (2005). Mechanical strain opens connexin 43 hemichannels in osteocytes: a novel mechanism for the release of prostaglandin. Mol. Biol. Cell 16, 3100-3106. doi: 10.1091/mbc.E04-10-0912

Chew, S. S., Johnson, C. S., Green, C. R., and Danesh-Meyer, H. V. (2010). Role of connexin43 in central nervous system injury. Exp. Neurol. 225, 250-261. doi: 10.1016/j.expneurol.2010.07.014

Cicirata, F., Parenti, R., Spinella, F., Giglio, S., Tuorto, F., Zuffardi, O., et al. (2000). Genomic organization and chromosomal localization of the mouse Connexin36 (mCx36) gene. Gene 251, 123-130. doi: 10.1016/S0378-1119(00)00202-X

Cina, C., Bechberger, J. F., Ozog, M. A., and Naus, C. C. (2007). Expression of connexins in embryonic mouse neocortical development. J. Comp. Neurol. 504, 298-313. doi: 10.1002/cne.21426

Cina, C., Maass, K., Theis, M., Willecke, K., Bechberger, J. F., and Naus, C. C. (2009). Involvement of the cytoplasmic C-terminal domain of connexin43 in neuronal migration. J. Neurosci. 29, 2009-2021. doi: 10.1523/JNEUROSCI.5025-08.2009

Condorelli, D. F., Parenti, R., Spinella, F., Trovato Salinaro, A., Belluardo, N., Cardile, V., et al. (1998). Cloning of a new gap junction gene (Cx36) highly expressed in mammalian brain neurons. Eur. J. Neurosci. 10, 1202-1208. doi: 10.1046/j.1460-9568.1998.00163.x

Contreras, J. E., Sánchez, H. A., Véliz, L. P., Bukauskas, F. F., Bennett, M. V., and Sáez, J. C. (2004). Role of connexin-based gap junction channels and hemichannels in ischemia-induced cell death in nervous tissue. Brain Res. Brain Res. Rev. 47, 290-303. doi: 10.1016/j.brainresrev.2004.08.002

Cooper, C. D., and Lampe, P. D. (2002). Casein kinase 1 regulates connexin-43 gap junction assembly. J. Biol. Chem. 277, 44962-44968. doi: 10.1074/jbc.M209427200

Davidson, J. O., Green, C. R., Bennet, L., and Gunn, A. J. (2015a). Battle of the hemichannels-Connexins and Pannexins in ischemic brain injury. Int. J. Dev. Neurosci. 45, 66-74. doi: 10.1016/j.ijdevneu.2014.12.007

Davidson, J. O., Rout, A. L., Wassink, G., Yuill, C. A., Zhang, F. G., Green, C. R., et al. (2015b). Non-additive effects of delayed connexin hemichannel blockade and hypothermia after cerebral ischemia in near-term fetal sheep. J. Cereb. Blood Flow Metab. 35, 2052-2061. doi: 10.1038/jcbfm.2015.171

Davies, T. C., Barr, K. J., Jones, D. H., Zhu, D., and Kidder, G. M. (1996) Multiple members of the connexin gene family participate in preimplantation development of the mouse. Dev. Genet. 18, 234-243. doi: 10.1002/(SICI)15206408(1996)18:3<234::AID-DVG4>3.0.CO;2-A

De Bock, M., Leybaert, L., and Giaume, C. (2017). Connexin channels at the gliovascular interface: gatekeepers of the brain. Neurochem. Res. 42, 2519-2536. doi: 10.1007/s11064-017-2313-x

Decrock, E., De Bock, M., Wang, N., Bol, M., Gadicherla, A. K., and Leybaert, L. (2015a). Electroporation loading of membrane-impermeable molecules to investigate intra- and intercellular $\mathrm{Ca} 2+$ signaling. Cold Spring Harb. Protoc. 2015, 284-288. doi: 10.1101/pdb.prot076562

Decrock, E., De Bock, M., Wang, N., Bultynck, G., Giaume, C., Naus, C. C., et al. (2015b). Connexin and pannexin signaling pathways, an architectural blueprint for CNS physiology and pathology? Cell. Mol. Life Sci. 72, 2823-2851. doi: 10.1007/s00018-015-1962-7

Dunn, C. A., and Lampe, P. D. (2014). Injury-triggered Akt phosphorylation of Cx43: a ZO-1-driven molecular switch that regulates gap junction size. J. Cell Sci. 127, 455-464. doi: 10.1242/jcs. 142497 
Elias, L. A., Wang, D. D., and Kriegstein, A. R. (2007). Gap junction adhesion is necessary for radial migration in the neocortex. Nature 448, 901-907. doi: $10.1038 /$ nature 06063

Gaietta, G., Deerinck, T. J., Adams, S. R., Bouwer, J., Tour, O., Laird, D. W., et al. (2002). Multicolor and electron microscopic imaging of connexin trafficking. Science 296, 503-507. doi: 10.1126/science.1068793

Giaume, C., Sáez, J. C., Song, W., Leybaert, L., and Naus, C. C. (2017). Connexins and pannexins in Alzheimer's disease. Neurosci. Lett. doi: 10.1016/j.neulet.2017.09.006. [Epub ahead of print].

Goodenough, D. A., Goliger, J. A., and Paul, D. L. (1996). Connexins, connexons, and intercellular communication. Annu. Rev. Biochem. 65, 475-502. doi: 10.1146/annurev.bi.65.070196.002355

Gulisano, M., Parenti, R., Spinella, F., and Cicirata, F. (2000). Cx36 is dynamically expressed during early development of mouse brain and nervous system. Neuroreport 11, 3823-3828. doi: 10.1097/00001756-200011270-00045

Haubrich, S., Schwarz, H. J., Bukauskas, F., Lichtenberg-Fraté, H., Traub, O., Weingart, R., et al. (1996). Incompatibility of connexin 40 and 43 Hemichannels in gap junctions between mammalian cells is determined by intracellular domains. Mol. Biol. Cell 7, 1995-2006. doi: 10.1091/mbc.7.12.1995

Jiang, J. X., and Gu, S. (2005). Gap junction- and hemichannelindependent actions of connexins. Biochim. Biophys. Acta 1711, 208-214. doi: 10.1016/j.bbamem.2004.10.001

Kandler, K., and Katz, L. C. (1998). Coordination of neuronal activity in developing visual cortex by gap junction-mediated biochemical communication. J. Neurosci. 18, 1419-1427.

Karagiannis, A., Sylantyev, S., Hadjihambi, A., Hosford, P. S., Kasparov, S., and Gourine, A. V. (2016). Hemichannel-mediated release of lactate. J. Cereb. Blood Flow Metab. 36, 1202-1211. doi: 10.1177/0271678X15611912

Kondo, R. P., Wang, S. Y., John, S. A., Weiss, J. N., and Goldhaber, J. I. (2000). Metabolic inhibition activates a non-selective current through connexin hemichannels in isolated ventricular myocytes. J. Mol. Cell. Cardiol. 32, 1859-1872. doi: 10.1006/jmcc.2000.1220

Kotini, M., and Mayor, R. (2015). Connexins in migration during development and cancer. Dev. Biol. 401, 143-151. doi: 10.1016/j.ydbio.2014.12.023

Koulakoff, A., Mei, X., Orellana, J. A., Saáez, J. C., and Giaume, C. (2012). Glial connexin expression and function in the context of Alzheimer's disease. Biochim. Biophys. Acta 1818, 2048-2057. doi: 10.1016/j.bbamem.2011.10.001

Krüger, O., Plum, A., Kim, J. S., Winterhager, E., Maxeiner, S., Hallas, G., et al. (2000). Defective vascular development in connexin 45-deficient mice. Development 127, 4179-4193.

Laird, D. W., Puranam, K. L., and Revel, J. P. (1991). Turnover and phosphorylation dynamics of connexin43 gap junction protein in cultured cardiac myocytes. Biochem. J. 273(Pt 1), 67-72. doi: 10.1042/bj2730067

Lampe, P. D. (1994). Analyzing phorbol ester effects on gap junctional communication: a dramatic inhibition of assembly. J. Cell Biol. 127, 1895-1905. doi: $10.1083 /$ jcb.127.6.1895

Lapato, A. S., and Tiwari-Woodruff, S. K. (2017). Connexins and pannexins: at the junction of neuro-glial homeostasis \& disease. J. Neurosci. Res. 96, 31-44. doi: $10.1002 /$ jnr. 24088

Leung, D. S., Unsicker, K., and Reuss, B. (2002). Expression and developmental regulation of gap junction connexins cx26, cx32, cx43 and cx45 in the rat midbrain-floor. Int. J. Dev. Neurosci. 20, 63-75. doi: 10.1016/S0736-5748(01)00056-9

Li, H., He, J., Yu, H., Green, C. R., and Chang, J. (2016). Bioglass promotes wound healing by affecting gap junction connexin 43 mediated endothelial cell behavior. Biomaterials 84, 64-75. doi: 10.1016/j.biomaterials.2016.01.033

Li, X., Zhao, H., Tan, X., Kostrzewa, R. M., Du, G., Chen, Y., et al. (2015). Inhibition of connexin43 improves functional recovery after ischemic brain injury in neonatal rats. Glia 63, 1553-1567. doi: 10.1002/glia.22826

Lin, J. H., Takano, T., Cotrina, M. L., Arcuino, G., Kang, J., Liu, S., et al. (2002). Connexin 43 enhances the adhesivity and mediates the invasion of malignant glioma cells. J. Neurosci. 22, 4302-4311.

Lin, J. H., Weigel, H., Cotrina, M. L., Liu, S., Bueno, E., Hansen, A. J., et al. (1998). Gap-junction-mediated propagation and amplification of cell injury. Nat. Neurosci. 1, 494-500. doi: 10.1038/2210

Liu, Z., Xu, D., Wang, S., Chen, Y., Li, Z., Gao, X., et al. (2017). Astrocytes induce proliferation of oligodendrocyte progenitor cells via connexin 47-mediated activation of the ERK/Id4 pathway. Cell Cycle 16, 714-722. doi: 10.1080/15384101.2017.1295183

Marins, M., Xavier, A. L., Viana, N. B., Fortes, F. S., Fróes, M. M., and Menezes, J. R. (2009). Gap junctions are involved in cell migration in the early postnatal subventricular zone. Dev. Neurobiol. 69, 715-730. doi: 10.1002/dneu.20737

Markoullis, K., Sargiannidou, I., Gardner, C., Hadjisavvas, A., Reynolds, R., and Kleopa, K. A. (2012). Disruption of oligodendrocyte gap junctions in experimental autoimmune encephalomyelitis. Glia 60, 1053-1066. doi: $10.1002 /$ glia.22334

Márquez-Rosado, L., Solan, J. L., Dunn, C. A., Norris, R. P., and Lampe, P. D. (2012). Connexin43 phosphorylation in brain, cardiac, endothelial and epithelial tissues. Biochim. Biophys. Acta 1818, 1985-1992. doi: 10.1016/j.bbamem.2011.07.028

Matsuuchi, L., and Naus, C. C. (2013). Gap junction proteins on the move: connexins, the cytoskeleton and migration. Biochim. Biophys. Acta 1828, 94-108. doi: 10.1016/j.bbamem.2012.05.014

Nagy, J. I., Ionescu, A. V., Lynn, B. D., and Rash, J. E. (2003a). Connexin29 and connexin32 at oligodendrocyte and astrocyte gap junctions and in myelin of the mouse central nervous system. J. Comp. Neurol. 464, 356-370. doi: 10.1002/cne.10797

Nagy, J. I., Ionescu, A. V., Lynn, B. D., and Rash, J. E. (2003b). Coupling of astrocyte connexins $\mathrm{Cx} 26, \mathrm{Cx} 30, \mathrm{Cx} 43$ to oligodendrocyte $\mathrm{Cx} 29, \mathrm{Cx} 32, \mathrm{Cx} 47$ : implications from normal and connexin 32 knockout mice. Glia 44, 205-218. doi: $10.1002 /$ glia.10278

Nagy, J. I., Li, W., Hertzberg, E. L., and Marotta, C. A. (1996). Elevated connexin43 immunoreactivity at sites of amyloid plaques in Alzheimer's disease. Brain Res. 717, 173-178. doi: 10.1016/0006-8993(95)01526-4

Nakase, T., Maeda, T., Yoshida, Y., and Nagata, K. (2009). Ischemia alters the expression of connexins in the aged human brain. J. Biomed. Biotechnol. 2009:147946. doi: 10.1155/2009/147946

Nishii, K., Shibata, Y., and Kobayashi, Y. (2014). Connexin mutant embryonic stem cells and human diseases. World J. Stem Cells 6, 571-578. doi: 10.4252/wjsc.v6.i5.571

O'Carroll, S. J., Gorrie, C. A., Velamoor, S., Green, C. R., and Nicholson, L. F. (2013). Connexin43 mimetic peptide is neuroprotective and improves function following spinal cord injury. Neurosci. Res. 75, 256-267. doi: 10.1016/j.neures.2013.01.004

Orellana, J. A., Avendaño, B. C., and Montero, T. D. (2014). Role of connexins and pannexins in ischemic stroke. Curr. Med. Chem. 21, 2165-2182. doi: 10.2174/0929867321666131228191714

Orellana, J. A., Figueroa, X. F., Sánchez, H. A., Contreras-Duarte, S., Velarde, V., and Sáez, J. C. (2011a). Hemichannels in the neurovascular unit and white matter under normal and inflamed conditions. CNS Neurol. Disord. Drug Targets 10, 404-414. doi: 10.2174/187152711794653869

Orellana, J. A., Hernández, D. E., Ezan, P., Velarde, V., Bennett, M. V., Giaume, C., et al. (2010). Hypoxia in high glucose followed by reoxygenation in normal glucose reduces the viability of cortical astrocytes through increased permeability of connexin 43 hemichannels. Glia 58, 329-343. doi: 10.1002/glia.20926

Orellana, J. A., Sãez, P. J., Shoji, K. F., Schalper, K. A., Palacios-Prado, N., Velarde, V., et al. (2009). Modulation of brain hemichannels and gap junction channels by pro-inflammatory agents and their possible role in neurodegeneration. Antioxid. Redox Signal. 11, 369-399. doi: 10.1089/ars.2008.2130

Orellana, J. A., Shoji, K. F., Abudara, V., Ezan, P., Amigou, E., Sáez, P. J., et al. (2011b). Amyloid beta-induced death in neurons involves glial and neuronal hemichannels. J. Neurosci. 31, 4962-4977. doi: 10.1523/JNEUROSCI.6417-10.2011

Parenti, R., Cicirata, F., Zappalà, A., Catania, A., La Delia, F., Cicirata, V., et al. (2010). Dynamic expression of $\mathrm{Cx} 47$ in mouse brain development and in the cuprizone model of myelin plasticity. Glia 58, 1594-1609. doi: $10.1002 /$ glia.21032

Parenti, R., Gulisano, M., Zappala, A., and Cicirata, F. (2000). Expression of connexin36 mRNA in adult rodent brain. Neuroreport 11, 1497-1502. doi: 10.1097/00001756-200005150-00028

Pellerin, L., Bouzier-Sore, A. K., Aubert, A., Serres, S., Merle, M., Costalat, R., et al. (2007). Activity-dependent regulation of energy metabolism by astrocytes: an update. Glia 55, 1251-1262. doi: 10.1002/glia.20528 
Perlman, I., and Ammermüller, J. (1994). Receptive-field size of L1 horizontal cells in the turtle retina: effects of dopamine and background light. J. Neurophysiol. 72, 2786-2795.

Retamal, M. A., Froger, N., Palacios-Prado, N., Ezan, P., Sáez, P. J., Sáez, J. C., et al. (2007). Cx43 hemichannels and gap junction channels in astrocytes are regulated oppositely by proinflammatory cytokines released from activated microglia. J. Neurosci. 27, 13781-13792. doi: 10.1523/JNEUROSCI.2042-07.2007

Richards, T. S., Dunn, C. A., Carter, W. G., Usui, M. L., Olerud, J. E., and Lampe, P. D. (2004). Protein kinase C spatially and temporally regulates gap junctional communication during human wound repair via phosphorylation of connexin 43 on serine368. J. Cell Biol. 167, 555-562. doi: 10.1083/jcb.200404142

Rimkute, L., Jotautis, V., Marandykina, A., Sveikatiene, R., Antanaviciute, I., and Skeberdis, V. A. (2016). The role of neural connexins in HeLa cell mobility and intercellular communication through tunneling tubes. BMC Cell Biol. 17:3. doi: $10.1186 / \mathrm{s} 12860-016-0080-1$

Roerig, B., and Feller, M. B. (2000). Neurotransmitters and gap junctions in developing neural circuits. Brain Res. Brain Res. Rev. 32, 86-114. doi: 10.1016/S0165-0173(99)00069-7

Saidi Brikci-Nigassa, A., Clement, M. J., Ha-Duong, T., Adjadj, E., Ziani, L., Pastre, D., et al. (2012). Phosphorylation controls the interaction of the connexin $43 \mathrm{C}$ terminal domain with tubulin and microtubules. Biochemistry 51, 4331-4342. doi: $10.1021 /$ bi201806j

Salas, D., Puebla, C., Lampe, P. D., Lavandero, S., and Sáez, J. C. (2015). Role of Akt and $\mathrm{Ca} 2+$ on cell permeabilization via connexin43 hemichannels induced by metabolic inhibition. Biochim. Biophys. Acta 1852, 1268-1277. doi: 10.1016/j.bbadis.2015.03.004

Salmina, A. B., Morgun, A. V., Kuvacheva, N. V., Lopatina, O. L., Komleva, Y. K., Malinovskaya, N. A., et al. (2014). Establishment of neurogenic microenvironment in the neurovascular unit: the connexin 43 story. Rev. Neurosci. 25, 97-111. doi: 10.1515/revneuro-2013-0044

Schultz, J. G., Andersen, S., Andersen, A., Nielsen-Kudsk, J. E., and Nielsen, J. M. (2016). Evaluation of cardiac electrophysiological properties in an experimental model of right ventricular hypertrophy and failure. Cardiol. Young 26, 451-458. doi: $10.1017 /$ S1047951115000402

Schulz, R., Görge, P. M., Görbe, A., Ferdinandy, P., Lampe, P. D., and Leybaert, L. (2015). Connexin 43 is an emerging therapeutic target in ischemia/reperfusion injury, cardioprotection and neuroprotection. Pharmacol. Ther. 153, 90-106. doi: 10.1016/j.pharmthera.2015.06.005

Spray, D. C., Ye, Z. C., and Ransom, B. R. (2006). Functional connexin "hemichannels": a critical appraisal. Glia 54, 758-773. doi: 10.1002/glia.20429

Suzuki, H., Ono, K., and Sawada, M. (2014). Protective effect of INI-0602, a gap junction inhibitor, on dopaminergic neurodegeneration of mice with unilateral 6-hydroxydopamine injection. J. Neural Transm. 121, 1349-1355. doi: $10.1007 / \mathrm{s} 00702-014-1209-\mathrm{z}$

Takeuchi, H., Jin, S., Suzuki, H., Doi, Y., Liang, J., Kawanokuchi, J., et al. (2008). Blockade of microglial glutamate release protects against ischemic brain injury. Exp. Neurol. 214, 144-146. doi: 10.1016/j.expneurol.2008.08.001

Takeuchi, H., Jin, S., Wang, J., Zhang, G., Kawanokuchi, J., Kuno, R., et al. (2006). Tumor necrosis factor-alpha induces neurotoxicity via glutamate release from hemichannels of activated microglia in an autocrine manner. J. Biol. Chem. 281, 21362-21368. doi: 10.1074/jbc.M600504200

Takeuchi, H., Mizoguchi, H., Doi, Y., Jin, S., Noda, M., Liang, J., et al. (2011). Blockade of gap junction hemichannel suppresses disease progression in mouse models of amyotrophic lateral sclerosis and Alzheimer's disease. PLoS ONE 6:e21108. doi: 10.1371/journal.pone.0021108
Thompson, R. J., Jackson, M. F., Olah, M. E., Rungta, R. L., Hines, D. J., Beazely, M. A., et al. (2008). Activation of pannexin-1 hemichannels augments aberrant bursting in the hippocampus. Science 322, 1555-1559. doi: 10.1126/science.1165209

Vicario, N., Calabrese, G., Zappalà, A., Parenti, C., Forte, S., Graziano, A. C. E., et al. (2017). Inhibition of Cx43 mediates protective effects on hypoxic/reoxygenated human neuroblastoma cells. J. Cell. Mol. Med. 21, 2563-2572. doi: $10.1111 / \mathrm{jcmm} .13177$

Wang, W. K., Chen, M. C., Leong, H. F., Kuo, Y. L., Kuo, C. Y., and Lee, C. H. (2014). Connexin 43 suppresses tumor angiogenesis by down-regulation of vascular endothelial growth factor via hypoxic-induced factor-1alpha. Int. J. Mol. Sci. 16, 439-451. doi: 10.3390/ijms16010439

Wang, Y., and Belousov, A. B. (2011). Deletion of neuronal gap junction protein connexin 36 impairs hippocampal LTP. Neurosci. Lett. 502, 30-32. doi: 10.1016/j.neulet.2011.07.018

White, T. W., and Bruzzone, R. (1996). Multiple connexin proteins in single intercellular channels: connexin compatibility and functional consequences. $J$. Bioenerg. Biomembr. 28, 339-350. doi: 10.1007/BF02110110

Willecke, K., Eiberger, J., Degen, J., Eckardt, D., Romualdi, A., Güldenagel, M., et al. (2002). Structural and functional diversity of connexin genes in the mouse and human genome. Biol. Chem. 383, 725-737. doi: 10.1515/BC. 2002.076

Wong, P., Tan, T., Chan, C., Laxton, V., Chan, Y. W., Liu, T., et al. (2016). The role of connexins in wound healing and repair: novel therapeutic approaches. Front. Physiol. 7:596. doi: 10.3389/fphys.2016.00596

Yawata, I., Takeuchi, H., Doi, Y., Liang, J., Mizuno, T., and Suzumura, A. (2008). Macrophage-induced neurotoxicity is mediated by glutamate and attenuated by glutaminase inhibitors and gap junction inhibitors. Life Sci. 82, 1111-1116. doi: $10.1016 /$ j.lfs.2008.03.010

Yoon, J. J., Green, C. R., O'Carroll, S. J., and Nicholson, L. F. (2010). Dose-dependent protective effect of connexin 43 mimetic peptide against neurodegeneration in an ex vivo model of epileptiform lesion. Epilepsy Res. 92, 153-162. doi: 10.1016/j.eplepsyres.2010.08.014

Zappalà, A., Parenti, R., La Delia, F., Cicirata, V., and Cicirata, F. (2010) Expression of connexin57 in mouse development and in harmalinetremor model. Neuroscience 171, 1-11. doi: 10.1016/j.neuroscience.2010. 09.010

Zhou, J. Z., and Jiang, J. X. (2014). Gap junction and hemichannel-independent actions of connexins on cell and tissue functions-an update. FEBS Lett. 588, 1186-1192. doi: 10.1016/j.febslet.2014.01.001

Zlomuzica, A., Viggiano, D., Degen, J., Binder, S., Ruocco, L. A., Sadile, A. G., et al. (2012). Behavioral alterations and changes in $\mathrm{Ca} /$ calmodulin kinase II levels in the striatum of connexin36 deficient mice. Behav. Brain Res. 226, 293-300. doi: 10.1016/j.bbr.2011.08.028

Conflict of Interest Statement: The authors declare that the research was conducted in the absence of any commercial or financial relationships that could be construed as a potential conflict of interest.

Copyright (c) 2017 Vicario, Zappalà, Calabrese, Gulino, Parenti, Gulisano and Parenti. This is an open-access article distributed under the terms of the Creative Commons Attribution License (CC BY). The use, distribution or reproduction in other forums is permitted, provided the original author(s) or licensor are credited and that the original publication in this journal is cited, in accordance with accepted academic practice. No use, distribution or reproduction is permitted which does not comply with these terms. 